\title{
Metformin - A Panacea Pharmaceutical Agent through convergence revolution initiative
}

\author{
Sonia Prabhakaran ${ }^{1}$, Dhiviya Thirumal ${ }^{2}$, Jolius Gimbun ${ }^{3,4}$, Balu Ranganathan ${ }^{5}$ \\ ${ }^{1}$ Department of Biotechnology, Sri Venkateswara College of Engineering, Pennalur, Kancheepuram District, \\ Sriperambudur - 602117, Tamil Nadu, India \\ ${ }^{2}$ Department of Medicine, Karpaga Vinayaga Institute of Medical Sciences and Research Center, Chinna \\ Kolambakkam, Palayanoor P.O, Kanchipuram Dist, Madurantagam - 603308, Tamil Nadu, India \\ ${ }^{3}$ Faculty of Chemical and Natural Resources Engineering, University Malaysia Pahang, Gambang Campus, \\ Gambang - 26300, Malaysia \\ ${ }^{4}$ Centre of Excellence for Advanced Research in Fluid Flow (CARIFF), University Malaysia Pahang, Gambang \\ Campus, Gambang - 26300, Malaysia \\ ${ }^{5}$ Palms Connect Sdn Bhd, Shah Alam - 40460, Selangor Darul Ehsan, Malaysia
}

\begin{abstract}
Metformin has been known to the mankind for centuries. Metformin is the first line of drug of choice for the treatment of type 2 diabetes. Initial pharmaceutical therapy was for treating the frequent urinal problem which is a primary manifestation of diabetes. At the time of writing, metformin as an intervention is looked into for cardiovascular risks, polycystic ovary syndrome and breast cancer. Annual demand for Metformin is 23,000 Metric tons per annum. Nano Drug Delivery Systems (NDDS) has embarked into Metformin controlled and targeted delivery for breast cancer, pancreatic cancer and non-small cell lung cancer. Clinical estimation of the biological fluids by the FDA approved diagnostic laboratories use LC-MS/MS where blood samples estimate Metformin as an intact molecule easing the pressure of clinical trials result. Metformin was manufactured by a less known and low profile Aoron pharmaceutical, France not aware of the block buster drug hence the potential of technology development start-ups can neither be underwritten nor underestimated even when there is a very high rate ( $90 \%$ ) of failed biotech/biomed start-up ventures. The bloom of the French lilac (metformin) to blossom and flower for the cure of breast cancer by convergence revolution initiative with the integration of academia, hospital, technology business incubator, multinational corporation with the deliverance of a start-up company
\end{abstract}

Keywords: Antineoplastic Drug, Breast Cancer, Clinical Trials, Metformin, Start-Up Company

\section{Introduction}

Metformin is the oral antihyperglycaemic drug of choice for type 2 diabetes mellitus treatment. This drug is unique from other oral antihyperglycaemic agents in the sense that this drug of choice not only subdues hepatic glucose production, reduces the intestinal glucose absorption and to a further extent improves insulin sensitivity. This drug proves further uniqueness in not causing hyperinsulinaemia. In-vitro and in-vivo studies suggest for a direct connectivity between diabetes and oncological manifestations. This review works and moves in the direction to depict metformin being an oral antihyperglycaemic drug at some point of time may act also as an anticancer drug wherein this combinatorial property is not exhibited by other antihyperglycaemic drugs. In the scope of this article, convergence revolution initiates the integration (rather than as collaboration) of chemical engineering, biotechnology, medicine with the aid of multinational corporation, hospital, technology

\footnotetext{
${ }^{*}$ Author for correspondence

Email: ranga@palmsconnect.com
} 
business incubator, philanthropic foundation and startup company with the best ability to forge a new innovative initiative path for the technology development for the cure of breast cancer. This is very much depicted by the authors of this article who are chemical engineers, bioengineers, design engineers, biotechnologists, design engineer medical practitioners (both specialized and budding), philanthropists, technology developers and big data analysts. More integration from regulators, onco-psychologists and federal funders would further accelerate for the cure of breast cancer with the classical example of cancer moonshot initiative.

\section{History}

Medieval Europe used Galega officinalis Lin possessing white, blue or purple flowers as an extract to be used as an herbal medicine. Chemical analysis revealed guanidine and associated compounds were found to be abundant in the extracts of Galega officinalis Lin dating back to mid-1800s. The plant is also called as goat's rue, French lilac (Figure 1), Spanish sanfoin and false indigo.

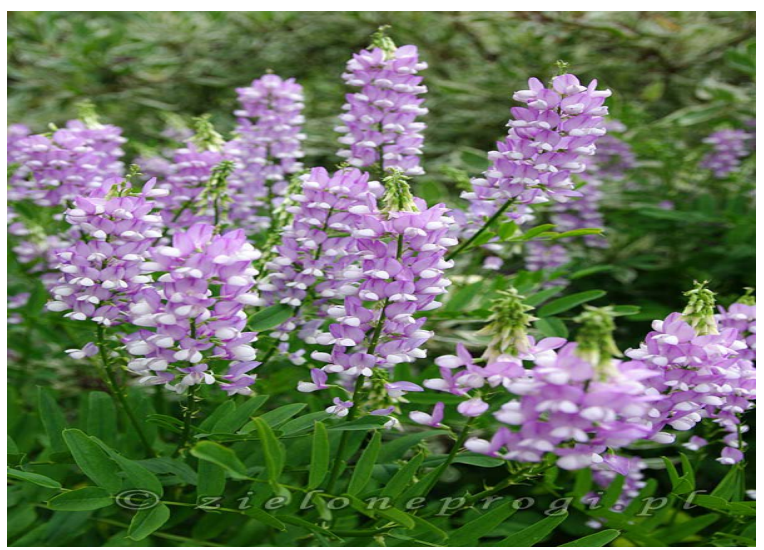

Fig. 1. Bloom of French Lilac.

In 1918, belonging to a class of drugs that has been part of the human apothecary for 500 years, guanidine

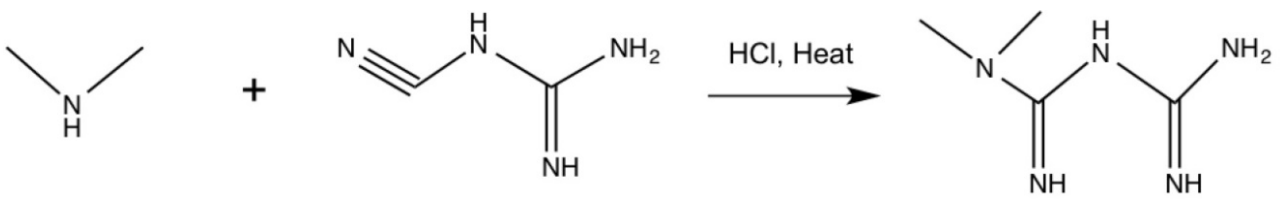

Fig. 2. Chemical reaction of Metformin production.

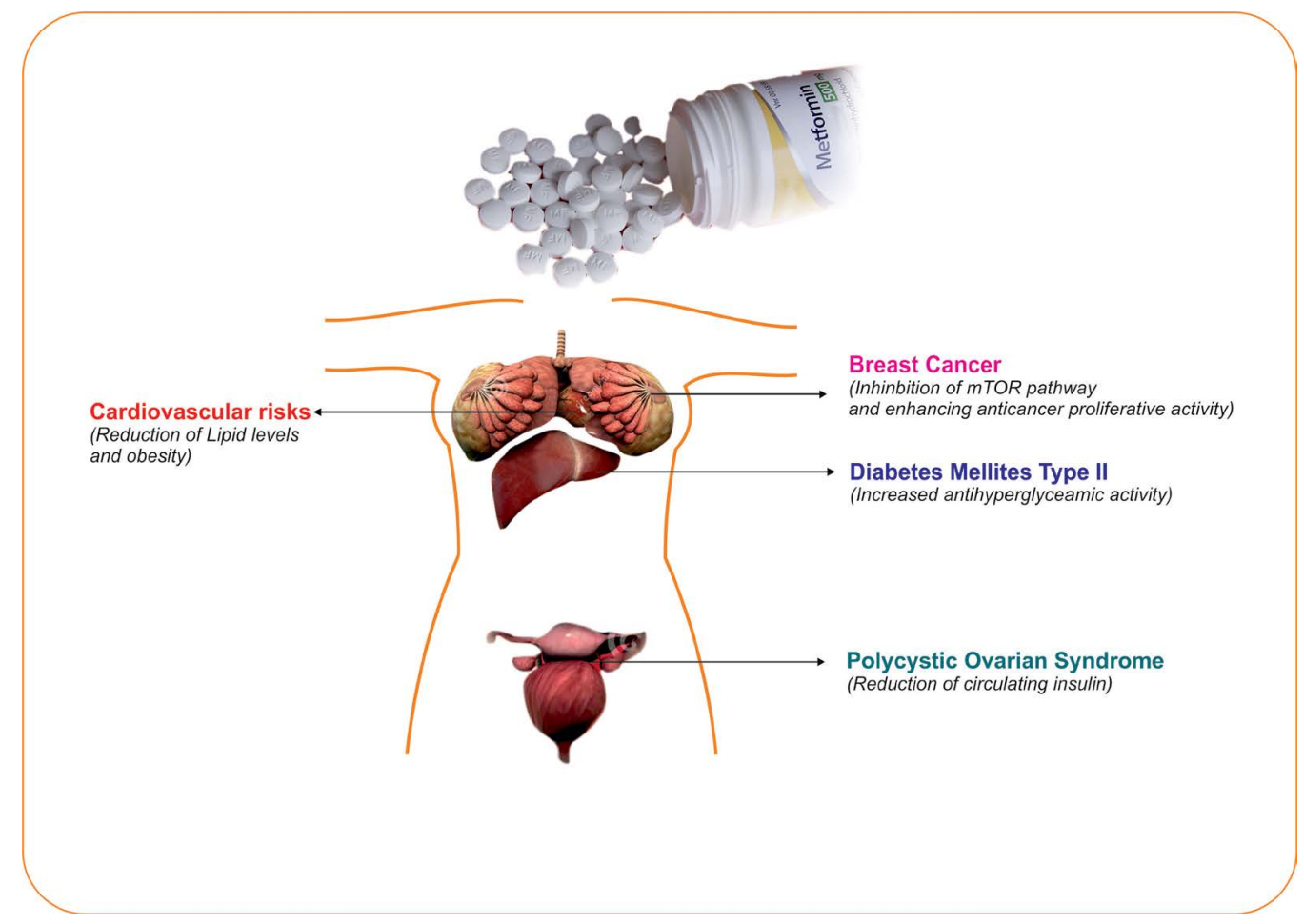

Fig. 3. Panacea action of Metformin. 
was reportedly ${ }^{1}$ reduced blood glucose levels in animal models. The chemical itself was first reported in 1922 by the Dublin chemists Emil Werner and James Bell ${ }^{2,3}$.

Metformin was rediscovered in the search for antimalarial agents in the 1940s and, during clinical tests, proved useful to treat influenza when it sometimes lowered blood glucose.

First report on the clinical use of metformin for the treatment of diabetes was in 1957 by the French physician Jean Sterne. A French company called Aron Laboratories, situated in Suresnes, Paris, France granted permission Jean Sterne to carry out his clinical trials experiments. Sterne selected dimethylbiguanide (metformin) for clinical development and proposed the name 'Glucophage' (glucose eater) ${ }^{4}$.

Jean Sterne's scientific temperament, administrative mettle with sharp enquiring mind facilitated the pragmatic prodigious experimentation appended by his perceptive clinical sixth sense transformed the blood-glucose diminutive potential of metformin into a therapeutic commercial success culminating him into a visionary.

\section{United States Scenario}

After several decades only United States of America was able to use metformin after FDA approved metformin in 1994, Bristol-Myers Squibb has applied (Application number: 020357/S010) for metformin ${ }^{5}$. An important clinical trials of metformin was carried out in 1995 in USA immediately after the FDA approval ${ }^{6}$.

Currently it is estimated that approximately, 37,000 metric tons of metformin is manufactured and mostly in FDA approved pharmaceutical companies in India.

\section{Clinico Pharmacology}

\subsection{Chemical Synthesis}

Synthesis of metformin dates back to 1920s (Figure 2), when metformin was synthesized using a single step process involving the reaction of dimethylamine hydrochloride and 2-cyanoguanidine (dicyandiamide) upon heating at increased temperature levels. Equimolar quantities of dimethylamine and 2-cyanoguanidine are made into a solution using toluene as the solvent, with gradual addition equimolar amount of hydrogen chloride the solution starts boiling and upon cooling, precipitation occurs. The precipitate formed is N, N-dimethylimidodicarbonimidic diamide hydrochloride with a $96 \%$ yield which is Metformin hydrochloride ${ }^{2,3}$. Metformin hydrochloride (IUPAC: N, N-dimethylimidodicarbonimidic diamide hydrochloride) is the Active Pharmaceutical Ingredient (API) of the finished product of the oral antihyperglycemic drug used for the treatment and management of type 2-diabetes.

\section{Estimation of Metformin in Bio- logical Fluids}

Sensitive and specific methods for analysis of biguanides in biological fluids ${ }^{7,8}$ are essential to an evaluation of their safety and efficacy. Metformin can be determined in biological fluids by various methods. Early assays were based on spectrophotometry which has a low specificity and sensitivity.

Mass spectrometry has been developed but the equipment required is not generally available in a routine analytical laboratory. High performance liquid chromatography ${ }^{9-11}$ is now considered as the method of choice for the assay of metformin because of its simplicity, rapidity, high specificity, reproducibility and sensitivity. Quite recently the plasma concentration of metformin is being determined using Liquid chromatography tandem mass spectroscopy (LC-MS/MS System) ${ }^{12}$. Other methods for estimation of metformin from blood plasma includes Ion pair liquid chromatography ${ }^{13}$ and HPLC with spectrophotometric detection ${ }^{14}$.

\section{Pharmacological Actions}

Metformin is found to affect multiple key processes related to cell growth, proliferation, and survival. Metformin which is a panacea drug (Figure 3) has the potential to treat myriads of diseases which are type 2 diabetes mellitus, cardiovascular risks, life extension for pancreatic cancer patients, poly cystic ovarian syndrome, oncogenic tumors and now on the clinical trials for breast cancer. 


\subsection{Diabetes Mellitus}

For type 2 diabetes for more than half a century, the drug of choice is metformin, for it is an orally administered drug in the form of tablets. The well-known trade name is called as Glucophage ". The implicating factors associated with the manifestation of the type 2 diabetes are well counteracted by the panacea drug Metformin. This drug acts with maximum efficacy on the levels of glucose and lipids in blood. To be more specific with a scientific representation, the protective effects make this drug of choice to be more efficient in terms of the adverse metabolic side effects of the other drugs which results often in obesity. Under physiological conditions, if cells become insulin-resistant, they no longer respond to insulin release by absorbing glucose. More glucose stays in the bloodstream, a condition known as hyperglycemia. Metformin improves insulin sensitivity in the peripheral tissues and thereby controls excessive glucose production. Metformin has been prescribed to overcome obesity $^{15-18}$.

\subsection{Polycystic Ovarian Syndrome (PCOS)}

Metformin treats PCOS, major physiological manifestation of this syndrome being obesity and infertility. PCOS ${ }^{19,20}$ is linked with higher levels of circulating insulin, which is characteristic in type 2 diabetes. Several endocrine and metabolic physiological abnormalities like insulin resistance and systolic blood pressure have been countermanded by the oral administration of metformin. Insulin resistance occurs most often in people who have a family history of obesity and women who have PCOS. Sedentary lifestyle also contributes to insulin resistance. People with insulin resistance often gain weight. High insulin levels can increase hunger, people with high insulin levels gain weight. Since metformin is a drug which lowers insulin results in an improved weight loss. Metformin along with a structured lifestyle intervention ${ }^{21-23}$ improves insulin sensitivity through increasing muscle glucose uptake and use. Obstetrics and gynecological conditions like irregular menstrual cycles and delayed pregnancy has been reversed at the doses of $500 \mathrm{mg}$ to $850 \mathrm{mg}$ of metformin thrice a day.

\subsection{Cardio Vascular Risks}

Metformin treats cardiovascular risks in Diabetic as well as non-diabetic individuals. Several cardio vascular associated diseases like hypertension and hypofibrinolysis could be treated using metformin ${ }^{24}$. Metabolic abnormalities consociated with cardiovascular diseases in particular visceral obesity is also being tackled by metformin. These associated factors conduce the enhanced cardiovascular risks associated with patients suffering from type 2 diabetes. Thereby, regular medications with metformin reduce cardiovascular risk.

\subsection{Breast Cancer}

In the in-vitro breast cancer cell lines experimentations, hormone receptor subtypes of breast cancer, AMPK stimulation ${ }^{25-27}$ by metformin leads to total cell growth inhibition in Estrogen Receptor(ER)-positive in-vitro cell lines. In terms of ER-negative cell lines partial inhibition is observed. The drug's effects on these processes stem from both metabolic and intracellular-signaling activity. The action of metformin on cancer cell proliferation is associated with AMPK activation, reduced Mammalian Target of Rapamycin (mTOR) signaling and protein synthesis, as well as a variety of other responses including decreased epidermal growth factor receptor (EGFR), Src, and mitogen-activated protein kinase (MAPK) activation, decreased expression of cyclins, and increased expression of $\mathrm{p} 27^{28,29}$. Metformin has been found to induce apoptosis in certain cell lines derived from endometrial cancers, glioma, and triple negative breast tumors. Therefore from these mechanisms it is quite evident that metformin prevents cancer ${ }^{30,31}$. The panacea drug Metformin is still under clinical trials for breast cancer.

\subsection{Global Manufacturing Scenario}

Global population of has now reached 7.5 billion of which $8.5 \%$ are living with diabetes approximately 420 million are in need of antihyperglycemic drug. As per FDA's Drug Master File (DMF) filings there are 18 leading global metformin producers. The average plant capacity of each producer would be about 3800 tons per year. Currently it is estimated that approximately, 37,000 
metric tons of metformin is manufactured annually and mostly in FDA approved companies in India.

The generic Metformin is manufactured by 129 companies with 258 Brands of Generics of Metformin. Key API global manufacturers are: Bristol-Mayers Squibb, Shouguang Fukang Pharmaceutical, Harman Finochem, Vistin Pharma, Cr Double-Crane, Keyuan Pharmaceutical, Farmhispania Group, Shijiazhuang Polee Pharmaceutical, Merck Sante and Aarti Drugs.

\subsection{Mechanism of Action in Anticancer Activity}

At the time of working on this report writing, there has not been a substantial scientific evidence of molecular mechanistic pathway of anticancer activity of metformin. Several plausible molecular mechanistic pathway has been reported for metformin's antineoplastic action on the basis several in vitro studies.

Several proposed mechanisms are:

- Decreased LKB1 thereby a reduction AMPK levels resulting in mTOR activation followed by decreased S6 kinase activation ${ }^{32}$

- Increased expression of REDD1 resulting in diminished mTOR activation followed by decreased S6 kinase activation ${ }^{33}$

- Inhibition of STAT3 facilitating and enhancing apoptosis induction ${ }^{34}$

- Alteration of the expression oncological associated miRNAs namely, miRNA let7A and miRNA- $181^{35}$

Metformin affects cell signaling pathways directly or indirectly at multiple points. For this reason, the drug may be useful against numerous cancer types.

As it has been mentioned, metformin acting directly on cancer cells have been reported where the chemical moiety acts on the mitochondrial respiration resulting in the stimulation of AMP-Activated Protein Kinase (AMPK). This stimulation action cascades to the activation of liver kinase B1 (LKB1) ${ }^{36}$. The elemental upstream kinase of AMPK is being, LKB1. For regular maintenance of energy homeostasis in the cellular environment AMPK and $\mathrm{LKB1}^{37}$ are the necessary elements for the normal physiological activities.

The other mechanism being an indirect action more on the host cell metabolism where reduced activity of hepatic gluconeogenesis (AMPK mediated) resulting in lowered circulating insulin levels. Involvement of lowered activation of PI3K pathway mediated by insulin/ IGF-1 receptor ${ }^{38}$ has also been reported.

Mammalian target rapamycin complex 1 (mTORC1) suppression is mainly associated with the anticancer molecular action of metformin. Metabolism, growth and proliferation of cancer cells are the pivotal roles played by the mTOR. It is observed that mTORC1 pathway is inhibited by metformin.

Metformin inhibits Mtor pathway both by dependent and as well as independent of AMP-activated protein kinase activation as suggested by evidences. Tuberous sclerosis complex protein 2 (TSC2) $^{39}$ is phosphorylated by AMPK, which inhibits Mtorc. This inhibition of Mtorc leads to decreased activities of protein synthesis and finally at the macro level, the cell growth. Since AMPK directly phosphorylates Mtor, inhibition of Mtor could be independent on TSC2 ${ }^{39}$. Metformin directs the upregulation of AMP-activated protein kinase. This is the key molecule in the regulation of glucose and insulin levels. It also plays a role as an inhibitor of mTOR.

Metformin acts on the hepatic cells whereby decreasing the levels of glucose produced by the hepatic cellular action resulting in the bloodstream levels and also on the cellular uptake of insulin ${ }^{40}$. These molecular actions trigger a cascade of mechanisms at the molecular level leading to the down regulation of the Ras/Raf/ MEK/ERK. Also it triggers PI3K/AKT/mTOR signaling pathways ${ }^{41}$. Any one or both of the above mentioned pathways are regularly activated in different types of carcinogenesis.

Autophagy is activated by AMPK directly and indirectly activating ULK1. AMPK also appears to stimulate mitochondrial biogenesis by regulating PGC1a (a mitochondrial stimulator of metformin biogenesis) which in turn promotes gene transcription in mitochondria ${ }^{42}$.

The plausible mechanism pathways hypothized can give the federal funding agencies to give a thinking to approve and fund the technology development in animal models to increase and improve the efficacy of metformin as an antineoplastic drug.

\subsection{Controlled Release}

A novel drug delivery nanocomposite film based system made of poly(ethylene glycol)-blockpoly(propylene glycol)-block-poly(ethylene glycol) (BP) polymers 


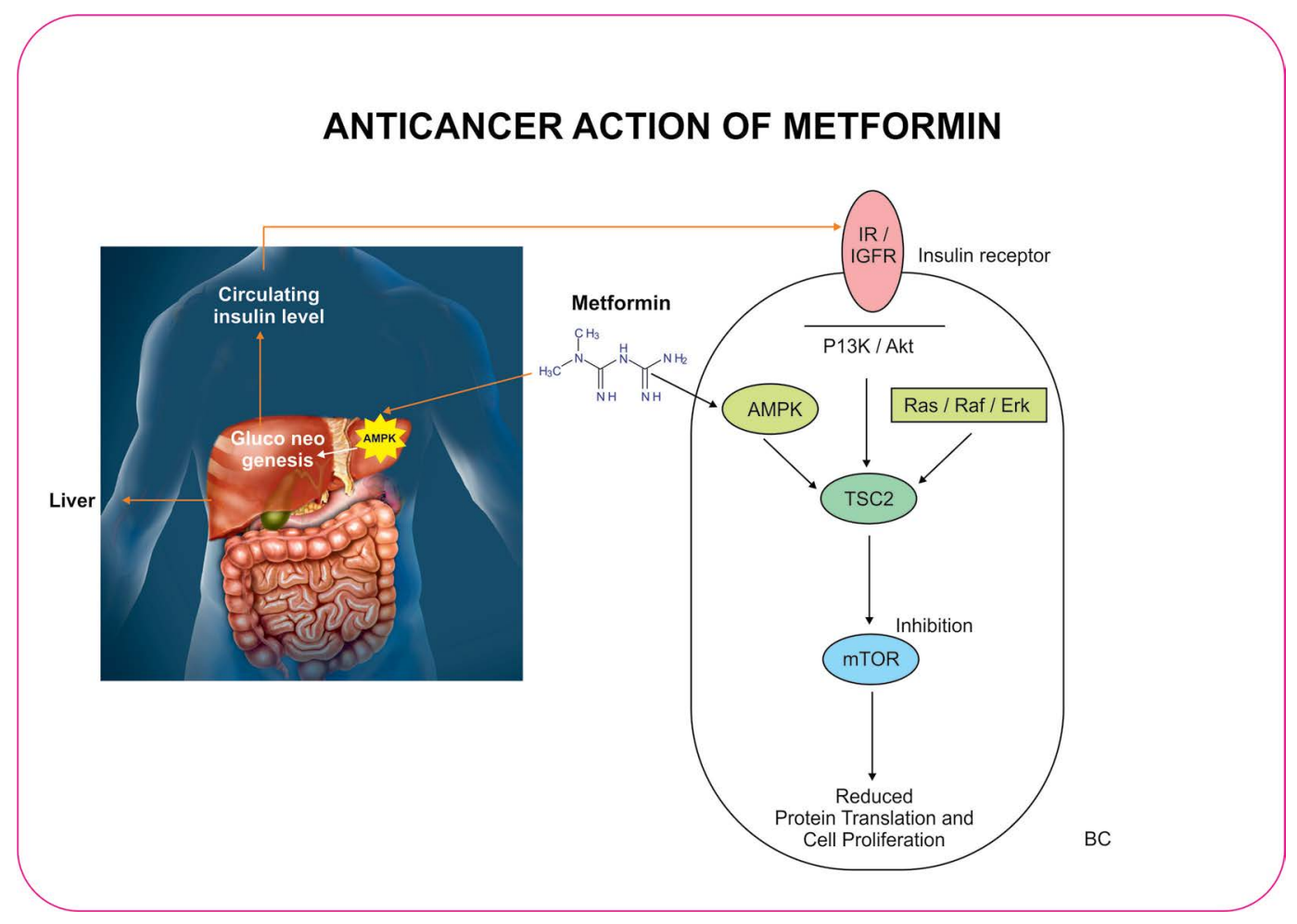

Fig. 4. Anticancer activity of metformin.

embedded with metformin and MCM-41 or MCM-41APS (APS = Aminopropylsilane) nanoparticles (NPs) was produced. A short burst release was observed by one day (22-24 hours) then a sustained controlled release for 15 days was observed. The film containing 4\%MCM-41-APS NPs had the slowest release (45\% release after 15 days $)^{43}$.

Co-encapsulation of cisplatin and metformin using Polyglutamic Acid (PGA) was synthesized. A cationic polymeric agent namely Polymeric Metformin (polymet) was used for the treatment of Non-Small Cell Lung Cancer (NSCLC). A cationic liposomes containing of DOTAP $^{44}$ (2,3-Dioleoyloxy-propyl)-trimethylammonium/ Cholesterol/DSPE-PEG-anisamide aminoethyl was used as the stabilizing agent. A synergistic action was observed whereby the tumor growth was suppressed by the mechanism of apoptosis NSCLC H460 tumor-bearing mice.

Table 1: List of clinical trials of metformin for breast cancer therapy

\begin{tabular}{|c|c|c|c|c|c|}
\hline ID & Intervention & Phase & Dosage $(\mathrm{mg})$ & Duration (weeks) & Outcome (primary) \\
\hline NCT00909506 & $\begin{array}{l}\text { Metformin } \\
\text { Placebo }\end{array}$ & II & \begin{tabular}{|l|}
$500 \mathrm{mg}$ \\
(once a day) \\
Placebo pill \\
(every morning) \\
Metformin $500 \mathrm{mg}$ \\
(every evening) \\
Escalation study: \\
Metformin $500 \mathrm{mg}$ \\
(every morning and evening) \\
\end{tabular} & $3-24$ & Weight loss \\
\hline NCT01266486 & $\begin{array}{l}\text { Metformin } \\
\text { (Extended } \\
\text { release) }\end{array}$ & II & \begin{tabular}{|l|} 
Extended release Metformin \\
(1500mg once daily)
\end{tabular} & $2-3$ & $\begin{array}{l}\text { Biomarkers: } \\
\text { S6K, } \\
\text { 4E-BP-1, } \\
\text { AMPK }\end{array}$ \\
\hline NCT00897884 & Metformin & NA & \begin{tabular}{|l|} 
Metformin \\
(500 mg) \\
Thrice daily
\end{tabular} & $2-3$ & $\begin{array}{l}\text { Cell proliferation } \\
\text { reduction }\end{array}$ \\
\hline
\end{tabular}


Ionic-gelation method was used for the synthesis of O-carboxymethyl chitosan (O-CMC) nanoparticles embedded with metformin. A therapy for pancreatic cancer was tried upon. Metformin embedded nanoparticles exhibited higher cytotoxicity on pancreatic cancer cell lines (MiaPaCa-2) ${ }^{45}$ in comparison with normal cell lines (L929) resulting in targeted delivery showing a prospective aspect of the synthesized nanoparticles.

Hyaluronic acid- Au nanoparticles embedded with metformin were synthesized for a potential therapy for liver cancer. Active targeting principle was exhibited for the apoptosis liver cancer (HepG2 cells) ${ }^{46}$. In terms of the dosage lower amount the nanoformulation was sufficient for $50 \%$ inhibition (IC50) when compared to the free metformin.

A different technique of electrospinning called emulsion electrospinning was used for the production of nanofiber scaffolds embedded with metformin hydrochloride. The nanocarriers are made of poly ( $\varepsilon$-caprolactone) (PCL) and Poly (3- Hydroxybutyric Acid-Co-3-Hydroxyvaleric Acid) (PHBV) ${ }^{47}$ organic biocompatible polymers. PCL nanocarriers were compared with PHBV nanocarriers for their controlled drug release efficiency. It has been reported that PCL nanofiber scaffold was able to deliver at a controlled way over a period of time and also with lowest burst release.

Metformin surface modified cellulose nanofibers (Met-Cel-NFs) were successfully prepared by attachment of metformin on the surface of cellulose nanofibers through electrostatic inter-action.

Gels composed of cellulose based nanofibers embedded with metformin were manufactured as a potential anti-metastasis novel nano drug delivery system for the prevention of human melanoma cancer metastasis. Mode of administration of this novel gel is quite easy in the sense Met-Cel-NFs gel ${ }^{48}$ could be sterilized easily and injected around or into the tumor.

\subsection{Clinical Trials}

\subsubsection{First Clinical Trial}

First clinical trials for metformin were carried out in Paris in 1957 for type 2 diabetes. Earlier years, metformin was called as glucophage ('glucose eater'). Clinical trials were so successful in the way blood glucose with type 2 diabetes was lowered but unaltered in the subjects who were non-diabetic.

A report published in 2005 reported the use of metformin decreased the risk of cancer by $23 \%{ }^{49}$. Moving forward, in 2012, substantial evidence was obtained with an insight for metformin as an antineoplastic agent ${ }^{50}$ (Figure 4).

Progression free survival (PFS), Relapse/Recurrence Free Survival (RFS), and Metastasis-Free Survival (MFS), combined together called as patient overall disease-free survival (OS) should be the major outcome of a clinical trial. FDA has not yet approved the use of metformin as a single chemotherapeutic agent for breast cancer but very much of a possibility in the near future. Insulin entered the commercial market nearly the same time when metformin was in the final stages and phase of clinical trials which really masked the greater panacea drug potential of metformin. Insulin was never tried as a stand-alone generic or even as an adjuvant for any other disease apart from diabetes but for good metformin is in the clinical trials for poly cystic ovary syndrome, anti-ageing, cardio vascular intervention and onco tumorogenesis especially breast cancer. Clinical trials in the direction of diabetic subjects suffering from breast cancer for which medication regimen is quite challenging when compared to non-diabetic subjects with breast cancer, metformin may become a panacea drug as we are getting very prospective clinical trials endpoint results. It is a well-known fact that elevated levels of glycolysis is observed in cancer patients in the scientific terms metabolism, glucose regulation and inflammation influence cancer manifestation outcomes especially breast cancer. Planning a clinical trial using metformin, metformin with a Breast Cancer Drug (BCD), only BCD and insulin with BCD should pave way for better understanding. By including two different categories of clinical trials breast cancer patient volunteers namely breast cancer patients with diabetes and breast cancer patients free of diabetes would provide a very informative insight for the panacea action of metformin for breast cancer.

As of date, there are six clinical trials (NCT0089788451, NCT01266486 $6^{52}$, NCT01650506 ${ }^{53}$, NCT00909506 ${ }^{54}$, NCT01885013 35 , NCT00659568 56 ) that have been completed using metformin as an intervention for breast cancer (Table 1). 
Of which three ${ }^{51-53}$ of the clinical trials have used metformin as a single intervention of choice. With supporting evidences based on several clinical trials, it is practically evident that metformin is used as a chemotherapeutic agent for tumor growth suppression (NCT0131023157, NCT0093057958) on breast cancer patients. With the advent of convergence revolution ${ }^{59}$ future of oncological interventions belongs to localized chemotherapy by the use nanocarriers ${ }^{60}$ using biocompatibe polymers ${ }^{61}$, hence metformin would be for more number of further clinical trials.

\section{Conclusion}

Principally by scientific evidence metformin molecular mechanistic action is by decreasing the glucose levels produced by the liver, reducing the bloodstream level and cascading by cellular uptake of insulin. In turn, the reduced insulin stimulation results in reduced activation of insulin receptors on cell membranes, triggering a cascade of intracellular molecular effects on various signal pathways. These pathways are often activated in many types of cancer cells. Cancer patient being treated for diabetes dwell with comorbidity ending up in psychological depression and financial ruin. Based on the in-vitro and in-vivo results there are a great potential to prescribe metformin as a combinatorial therapeutic agent. At the translational research level, in vitro and in vivo studies have supported the use of metformin in several cancer types and, along with tumor specimen biomarker studies, have begun to elucidate the molecular mechanisms of metformin's action. The bloom of the French lilac may be realized to blossom and flower in a new direction in the therapy for not only diabetes mellitus but also cardiovascular risks, polycystic ovarian syndrome, oncogenic tumors and of course for the cure of breast cancer.

\section{Conflict of Interest}

One of the authors, Balu Ranganathan discloses financial interest in Palms Connect Sdn Bhd, Malaysia holds stock options in the company.

\section{Authors Contributions:}

All the authors conceived the idea on convergence integration. S.P. and D.T worked and designed the figures. S.P and B.R. deliberated the manuscript subject matter and wrote the manuscript. B.R. revised the document upon reviewer comments.

\section{References}

1. Watanabe CK. Studies in the metabolic changes induced by administration of guanidine bases. J Biol Chem. 1918; 33:253-65.

2. Werner EA, Bell J. The preparation of guanidine by the interaction of Dicyanodiamide and ammonium thiocyanate. J Chem Soc Trans. 1920; 117:1133. https:// doi.org/10.1039/CT9201701133

3. Werner EA, Bell J. The Preparation of Methylguanidine, and of $\beta \beta$-Dimethylguanidine by the Interaction of Dicyanodiamide and Methylammonium and Dimethylammonium Chlorides Respectively. J Chem Soc Trans. 1922; 121:1790. https://doi.org/10.1039/ CT9222101790

4. Sterne J. Du nouveau dans les antidiabetiques. La NN Dimethylamine Guanyl guanide (NNDG). Maroc Med. 1957; 36:1295-6.

5. Available from: https://www.accessdata.fda.gov/drugsatfda docs/nda/98/020357s010.cfm

6. DeFronzo RA, Goodman AM. The multicenter metformin study group efficacy of metformin in patients with noninsulin-dependent diabetes mellitus New England. Journal Medicine. 1995; 333:541-9. https://doi.org/10.1056/ NEJM199508313330902 PMid:7623902

7. Lennard MS, Casey C, Tucker GT, Woods HF. Determination of metformin in biological samples. Br J clin Pharmac. 1978; 6:183-5. https://doi.org/10.1111/j.1365-2125.1978. tb00852.x

8. Gabr RQ, Padwal RS, Brocks DR. Determination of metformin in human plasma and urine by highperformance liquid chromatography using small sample volume and conventional octadecyl silane column. J Pharm Pharmaceut Sci. 2010; 13(4):486-494. https://doi. org/10.18433/J32C71

9. Frid A, Sterner GN, Londahl M, Wiklander C, Cato A, Vinge E, Andersson A. Novel assay of metformin levels in patients with type 2 diabetes and varying levels of renal function. Diabetes Care. 2010; 33(6):1291-2. https://doi.org/10.2337/dc09-1284 PMid:20215446 PMCid:PMC2875440

10. Kim HK, Park YS. Plasma concentration of metformin and dexamethasone after administration through osseogate. Drug Delivery. 2017; 24(1):437-42. https://doi.org/10.10 80/10717544.2016.1261380 PMid:28165808 
11. Santoro AB, Stage TB, Struchiner CJ, Christensen MM, Brosen K, Suarez-Kurtz G. Limited sampling strategy for determining metformin area under the plasma concentration-time curve. Br J Clin Pharmacol. 2016 82(4):1002-10. $\quad$ https://doi.org/10.1111/bcp.13049 PMid:27324407 PMCid:PMC5137825

12. Kumar PP, Murthy TE, Rao MVB. Development, validation of liquid chromatography-tandem mass spectrometry method for simultaneous determination of rosuvastatin and metformin in human plasma and its application to a pharmacokinetic study. J Adv Pharm Technol Res. 2015; 6(3):118-24. https://doi.org/10.4103/2231-4040.157982 PMid:26317076 PMCid:PMC4542398

13. Aburuz S, Millership J, Mcelnay J, Chromatogr B. Determination of metformin in plasma using a new ion pair solid phase extraction technique and ion pair liquid chromatography. Biomed Life Sci. 2003; 798:203-9. https://doi.org/10.1016/j.jchromb.2003.09.043

14. Cheng C, Chou C. Determination of metformin in human plasma by high-performance liquidchromatography with spectrophotometric detection. J Chromatogr B Biomed Sci Appl. 2001; 762(1):51-8. https://doi.org/10.1016/ S0378-4347(01)00342-5

15. DeCensi A, Puntoni $M$, Goodwin P, Cazzaniga $M$, Gennari A, Bonanni B, Gandini S. Metformin and Cancer risk in diabetic patients: A systematic review and metaanalysis. Cancer Prev Res. 2010; 3:1451-61. https:/doi. org/10.1158/1940-6207.CAPR-10-0157 PMid:20947488

16. Levri KM, Slaymaker E, Last A, Yeh J, Ference J, D’Amico F, Wilson SA. Metformin as treatment for overweight and obese adults: A systematic review. Annals of Family Medicine. 2005; 3(5):457-61. https://doi.org/10.1370/ afm.343 PMid:16189063 PMCid:PMC1466911

17. van der Aa MP, Hoving V, van de Garde EMW, Boer A, Knibbe CAJ, van der Vorst MMJ. The effect of eighteenmonth metformin treatment in obese adolescents: comparison of results obtained in daily practice with results from a clinical trial. Journal of Obesity. 2016. Article ID 7852648. https://doi.org/10.1155/2016/7852648 PMid:28101379 PMCid:PMC5214571

18. Pastor-Villaescusa B, Caballero-Villarraso J, Ca-ete MD, Hoyos R, et al. Evaluation of differential effects of metformin treatment in obese children according to pubertal stage and genetic variations: study protocol for a randomized controlled trial Trials. 2016; 17:323. https:// doi.org/10.1186/s13063-016-1403-4 PMid:27432166 PMCid:PMC4950074

19. Penzias A, Bendikson K, Butts S, et al. Role of metformin for ovulation induction in infertile patients with Polycystic
Ovary Syndrome (PCOS): A guideline. Fertil Steril. 2017; S0015-0282(17):30485-5.

20. Pedersen AJT, Stage TB Glintborg D, Andersen M, Christensen $\mathrm{MMH}$. The pharmacogenetics of metformin in women with PCOS: A randomized trial. Basic Clin Pharmacol Toxicol. 2017. https://doi.org/10.1111/bcpt.12874

21. O'Brien MJ, Perez A, Scanlan AB, Alos VA, et al. PREVENTDM comparative effectiveness trial of lifestyle intervention and metformin. Am J Prev Med. 2017; 52(6):788-97.https:// doi.org/10.1016/j.amepre.2017.01.008 PMid:28237635

22. O'Brien MJ, Whitaker RC, Yu D, Ackermann RT. The comparative efficacy of lifestyle intervention and metformin by educational attainment in the Diabetes Prevention Program. Prev Med. 2015; 77:125-30. https:// doi.org/10.1016/j.ypmed.2015.05.017～PMid:26024851 PMCid:PMC4490008

23. Florez H, Pan Q, Ackermann RT, Marrero DG, et al. Diabetes prevention program research group. Impact of lifestyle intervention and metformin on health-related quality of life: The diabetes prevention program randomized trial. J Gen Intern Med. 2012; 27(12):1594-601. https:// doi.org/10.1007/s11606-012-2122-5 PMid:22692637 PMCid:PMC3509296

24. The diabetes prevention program research group. Impact of intensive lifestyle and metformin therapy on cardiovascular disease risk factors in the diabetes prevention program. Diabetes Care. 2005; 28(4):888-94. https://doi.org/10.2337/diacare.28.4.888 PMid:15793191 PMCid:PMC1307521

25. Zakikhani M, Dowling R, Fantus GI, Sonenberg N, Pollak M. Metformin is an AMP Kinase- Dependent growth inhibitor for breast cancer cells. Cancer Res. 2006; 66(21):10269-73. https://doi.org/10.1158/0008-5472. CAN-06-1500 PMid:17062558

26. Dowling R, Zakikhani M, Fantus G, Pollak M, Sonenberg N. Metformin inhibits mammalian target of rapamycindependent translation initiation in breast cancer cells. Available from: http://www.mcgill.ca/pollak-lab/files/ pollak-lab/metformin_inhibits_mammalian_target_of_ rapamycin-dependent_translation_initiation_in_breast_ cancer_cells.pdf

27. Jiralerspong S, Palla SL, Giordano SH, et al. Metformin and pathologic complete responses to neoadjuvant chemotherapy in diabetic patients with breast cancer. Journal of Clinical Oncology. 2009; 27(20):3297-302. https://doi.org/10.1200/JCO.2009.19.6410 PMid:19487376 PMCid:PMC2736070

28. Goodwin PJ, Stambolic V, Lemieux J, Chen BE, et al. Evaluation of metformin in early breast cancer: A 
modification of the traditional paradigm for clinical testing of anti-cancer agents. Breast Cancer Research and Treatment. 2011; (126):215-20. https://doi.org/10.1007/ s10549-010-1224-1 PMid:20976543

29. NCT01101438 A Phase III randomized trial of metformin vs placebo in early stage breast cancer: 2010-2017. Available from: https://clinicaltrials.gov/ct2/show/NCT01101438

30. Lohmann AE, Liebman MF, Brien W, Parulekar WR, et al. Effects of metformin versus placebo on vitamin B12 metabolism in non-diabetic breast cancerpatients in CCTG MA.32. Breast Cancer Res Treat. 2017; 164(2):371-8. https://doi.org/10.1007/s10549-017-4265-x PMid:28447237

31. Campagnoli C, Pasanisi P, Abba C, Ambroggio S, et al. Effect of different doses of metformin on serum testosterone and insulin in non-diabetic women with breast cancer: a randomized study. Clin Breast Cancer. 2012; 12(3):175-82. https://doi.org/10.1016/j.clbc.2012.03.004 PMid:22607767

32. Shaw RJ, Kosmatka M, Bardeesy N, et al. The tumor suppressor LKB1 kinase directly activates AMP-activated kinase and regulates apoptosis in response to energy stress. Proc Natl Acad Sci USA. 2004; 101:3329-35. https://doi.org/10.1073/pnas.0308061100 PMid:14985505 PMCid:PMC373461

33. Katiyar S, Liu E, Knutzen CA, Lang ES, Christian R Lombardo CR, et al. REDD1, an inhibitor of mTOR signalling REDD1, is regulated by the CUL4A-DDB1 ubiquitin ligase. EMBO Reports. 2009; 10(8):866-72. https://doi.org/10.1038/embor.2009.93 PMid:19557001 PMCid:PMC2726664

34. Aryappalli P, Al-Qubaisi SS, Attoub S, George JA, Arafat K, Ramadi KB, Mohamed YA, Al-Dhaheri MM, Al-Sbiei A, Fernandez-Cabezudo MJ, Al-Ramadi BK. The IL-6/ STAT3 signaling pathway is an early target of manuka honey-induced suppression of human breast cancer cells. Frontiers in Oncology. 2017; 14(7):167. https:// doi.org/10.3389/fonc.2017.00167

PMid:28856117 PMCid:PMC5557744

35. Oliveras-Ferraros C, Cufí S, Vazquez-Martin A, TorresGarcia VZ, Del Barco S, Martin-Castillo B, Menendez JA. Micro(mi)RNA expression profile of breast cancer epithelial cells treated with the anti-diabetic drug metformin: Induction of the tumor suppressor miRNA let-7a and suppression of the TGF $\beta$-induced oncomiR miRNA-181a. Cell Cycle. 2011 Apr 1; 10(7):1144-51. https://doi.org/10.4161/cc.10.7.15210 PMid:21368581

36. Algire C, Amrein L, Bazile M, et al. Diet and tumor LKB1 expression interact to determine sensitivity to anti-neoplastic effects of metformin in vivo. Oncogene. 2011; 30:1174-82. https://doi.org/10.1038/onc.2010.483 PMid:21102522

37. Chiang GG, Abraham RT. Targeting the mTOR signaling network in cancer. Trends Mol Med 2007; 13:433-42. https:// doi.org/10.1016/j.molmed.2007.08.001 PMid:17905659

38. LeRoith D, Roberts CT Jr. Insulin-like growth factors and cancer. Ann Intern Med. 1995; 122:54-9. https:// doi.org/10.7326/0003-4819-122-1-199501010-00009 PMid:7619109

39. Liu H, Radisky DC, Nelson CM, Zhang H, Fata JE, Roth RA, Bissell MJ. Mechanism of Akt1 inhibition of breast cancer cell invasion reveals a protumorigenic role for TSC2. Proc Natl Acad Sci U S A. 2006; 103(11):4134-9. https://doi.org/10.1073/pnas.0511342103 PMid:16537497 PMCid:PMC1390746

40. Widen ElM, Eriksson JG, Groop LC. Metformin normalizes nonoxidative glucose metabolism in insulinresistant normoglycemic first-degree relatives of patients with NIDDM. Diabetes. 1992 Mar; 41:354-8. https://doi. org/10.2337/diab.41.3.354 PMid:1551495

41. Prager R, Schernthaner G, Graf H. Effect of metformin on peripheral insulin sensitivity in non insulin dependent diabetes mellitus. Diabete Metab. 1986 Dec; 12(6):346-50. PMid:3817257

42. Drzewoski J, Drozdowska A, Sliwińska A. Do we have enough data to confirm the link between antidiabetic drug use and cancer development? Pol Arch Med Wewn. 2011; 121:81-7. PMid:21430609

43. Shariatinia Z, Zahraee Z. Controlled release of metformin from chitosan-based nanocomposite films containing mesoporous MCM-41 nanoparticles as novel drug delivery systems. J Colloid Interface Sci. 2017; 501:60-76. https://doi.org/10.1016/j.jcis.2017.04.036 PMid:28433886

44. Xiong Y, Zhao Y, Miao L, Lin M, Huang L. Co-delivery of polymeric metformin and cisplatin by self-assembled core-membrane nanoparticles to treat non-small cell lung cancer. J Control Release. 2016; 244(Pt A):63-73.

45. Snima KS, Jayakumar R, Unnikrishnan AG, Nair SV, Lakshmanan VK. O-Carboxymethyl chitosan nanoparticles for metformin delivery to pancreatic cancer cells. Carbohydrate Polymers. 2012; 89:1003-7. https:// doi.org/10.1016/j.carbpol.2012.04.050 PMid:24750892

46. Kumar CS, Raja MD, Sundar DS, Antoniraj MG, Ruckmani K. Hyaluronic acid co-functionalized gold nanoparticle complex for the targeted delivery of metformin in the treatment of liver cancer (HepG2 cells). Carbohydrate Polymers. 2015; 128:63-74. https://doi.org/10.1016/j. carbpol.2015.04.010 PMid:26005140 
47. Hu J, Prabhakaran M, Tian L, Ding X, Ramakrishna S. Drugloaded emulsion electrospun nanofibers: Characterization, drug release and in vitro biocompatibility. RSC Adv. 2015; 5:100256. https://doi.org/10.1039/C5RA18535A

48. Nurani M, Akbari V, Taheri A. Preparation and characterization of metformin surface modifiedcellulose nanofiber gel and evaluation of its anti-metastatic potentials. Carbohydrate Polymers. 2017; 165:32233. https://doi.org/10.1016/j.carbpol.2017.02.067 PMid:28363556

49. Evans JM, Donnelly LA, Emslie-Smith AM, Alessi DR, Morris AD. Metformin and reduced risk of cancer in diabetic patients. BMJ. 2005 Jun 4; 330(7503):13045. $\quad$ https://doi.org/10.1136/bmj.38415.708634.F7 PMid:15849206 PMCid:PMC558205

50. Pollak MN. Investigating metformin for cancer prevention and treatment: The end of the beginning. Cancer Discov. 2012; 2(9):778-90. https://doi.org/10.1158/2159-8290. CD-12-0263 PMid:22926251

51. Clinical and biologic effects of metformin in early stage breast cancer 2008-2011. Available from: https:// clinicaltrials.gov/ct2/show/NCT00897884

52. Effect of metformin on breast cancer metabolism 20102014. Available from: https://clinicaltrials.gov/ct2/show/ NCT01266486

53. Study of erlotinib and metformin in triple negative breast cancer 2012-2017. Available from: https://clinicaltrials. gov/ct2/show/NCT01650506

54. Efficacy and safety of adjuvant metformin for operable breast cancer patients 2009-2015. Available from: https:// clinicaltrials.gov/ct2/show/NCT00909506
55. Myocet + Cyclophosphamide + Metformin Vs Myocet + Cyclophosphamide in 1st line treatment of HER2 Neg. Metastatic Breast Cancer Patients (MYME). 20132015. Available from: https://clinicaltrials.gov/ct2/show/ NCT01885013

56. Metformin and temsirolimus in treating patients with metastatic or unresectable solid tumor or lymphoma 2008-2013. Available from: https://clinicaltrials.gov/ct2/ show/NCT00659568

57. A trial of standard chemotherapy with metformin (vs placebo) in women with metastatic breast cancer 20112017. Available from: https://clinicaltrials.gov/ct2/show/ NCT01310231

58. Metformin pre-surgical pilot study 2009-2017. Available from: https:/clinicaltrials.gov/ct2/show/NCT00930579

59. Khargonekar P, Sinskey A, Miller C, Ranganathan B. Convergence revolution- Piloting the third scientific revolution through start-ups for breast cancer cure. Cancer Sci Res Open Access. 2017; 4(1):1-6. DOI: http://dx.doi. org/10.15226/csroa.2017.00130 https://doi.org/10.15226/ csroa.2017.00130

60. Ramakrishnan R, Gimbun J, Samsuri F, Narayanamurthy V, Gajendran N, Lakshmi YS, Stranska D, Ranganathan B. Needleless electrospinning technology- an entrepreneurial perspective. Indian J Sci Technol. 2016; 9:1-11. https:// doi.org/10.17485/ijst/2016/v9i15/91538

61. Ranganathan B, Miller C, Sinskey A. Biocompatible synthetic and semi-synthetic polymers- A patent preliminary analysis. Pharm Nanotechnol. 2017 Oct 23. DOI: $10.2174 / 2211738505666171023152549$. [Epub ahead of print]. 